\title{
Neurofibromatosis: part 2 - clinical management
}

\author{
Neurofibromatoses: parte 2 - manejo clínico \\ Sociedade Brasileira de Pesquisa em Neurofibromatoses (Alphabetical surname order of Authors): \\ Pollyanna Barros Batista', Eny Maria Goloni Bertollo², Danielle de Souza Costaํ', Lucas Eliam6 , Karin \\ Soares Gonçalves Cunha ${ }^{3}$, José Renan Cunha-Melo ${ }^{1}$, Luiz Guilherme Darrigo Junior ${ }^{4}$, Mauro Geller ${ }^{5}$, Ingrid \\ Faria Gianordoli-Nascimento', Luciana Gonçalves Madeira', Hérika Martins Mendes ${ }^{1}$, Débora Marques \\ de Miranda ${ }^{1}$, Nikolas Andre Mata-Machado7, Eric Grossi Morato', Érika Cristina Pavarino², Luciana \\ Baptista Pereira1, Nilton Alves de Rezende1, Luiza de Oliveira Rodrigues', Jorge Bezerra Cavalcanti Sette', \\ Carla Menezes da Silva ${ }^{1}$, Juliana Ferreira de Souza ${ }^{1}$, Márcio Leandro Ribeiro de Souza ${ }^{1}$, Aline Stangherlin \\ Martins', Eugênia Ribeiro Valadares', Paula Vieira Teixeira Vidigal', Vanessa Waisberg', Yehuda Waisberg', \\ Luiz Oswaldo Carneiro Rodrigues' (Coordinator)
}

\begin{abstract}
Part 1 of this guideline addressed the differential diagnosis of the neurofibromatoses (NF): neurofibromatosis type 1 (NF1), neurofibromatosis type 2 (NF2) and schwannomatosis (SCH). NF shares some features such as the genetic origin of the neural tumors and cutaneous manifestations, and affects nearly 80 thousand Brazilians. Increasing scientific knowledge on NF has allowed better clinical management and reduced rate of complications and morbidity, resulting in higher quality of life for NF patients. Most medical doctors are able to perform NF diagnosis, but the wide range of clinical manifestations and the inability to predict the onset or severity of new features, consequences, or complications make NF management a real clinical challenge, requiring the support of different specialists for proper treatment and genetic counseling, especially in NF2 and SCH. The present text suggests guidelines for the clinical management of NF, with emphasis on NF1.
\end{abstract}

Keywords: neurofibromatosis, neurofibromatosis type 1, neurofibromatosis type 2, schwannomatosis, Legius syndrome.

\section{RESUMO}

A primeira parte desta diretriz abordou o diagnóstico diferencial das neurofibromatoses (NF): neurofibromatose do tipo 1 (NF1), neurofibromatose do tipo 2 (NF2) e schwannomatose (SCH). As NF compartilham algumas características, como a origem neural dos tumores e sinais cutâneos, e afetam cerca de 80 mil brasileiros. 0 aumento do conhecimento científico sobre as NF tem permitido melhor manejo clínico e redução da morbidade das complicações, resultando em melhor qualidade de vida para os pacientes com NF. A maioria dos médicos é capaz de realizar o diagnóstico das NF, mas a variedade de manifestações clínicas e a dificuldade de se prever o surgimento e a gravidade de complicações, torna o manejo da NF um desafio para o clínico e envolve diferentes especialistas para o tratamento adequado e aconselhamento genético, especialmente a NF2 e a SCH. O presente texto sugere algumas orientações para o acompanhamento dos portadores de NF, com ênfase na NF1.

Palavras-chave: neurofibromatoses, neurofibromatose 1, neurofibromatose 2, schwannomatose, síndrome de Legius.

\footnotetext{
'Universidade Federal de Minas Gerais, Belo Horizonte MG, Brazil;

${ }^{2}$ Faculdade de Medicina de São José do Rio Preto, Sao Paulo SP, Brazil;

${ }^{3}$ Universidade Federal Fluminense, Faculdade de Medicina, Rio de Janeiro RJ, Brazil;

4Universidade de São Paulo, Faculdade de Medicina de Ribeirão Preto, Ribeirao Preto SP, Brazil;

${ }^{5}$ Universidade Federal do Rio de Janeiro, Faculdade de Medicina, Rio de Janeiro RJ, Brazil;

${ }^{6}$ Radiologia Anchieta, Brasília DF, Brazil;

${ }^{7}$ Loyola University of Chicago, USA.

Correspondence: Luiz Oswaldo Carneiro Rodrigues; Centro de Referência em Neurofibromatose, Hospital das Clínicas, Faculdade de Medicina da UFMG; Alameda Álvaro Celso, 55; 30150-260 Belo Horizonte MG, Brasil; E-mail: rodrigues.loc@gmail.com

Conflict of interest: There is no conflict of interest to declare.

Support: CNPq, FAPEMIG, FAPERJ and CAPES.

Received 30 January 2015; Accepted 20 February 2015.
} 
Part 1 of this guideline addressed differential diagnosis of the neurofibromatoses (NF): neurofibromatosis type 1 (NF1), neurofibromatosis type 2 (NF2) and schwannomatosis $(\mathrm{SCH})^{1}$. This second part aims to offer some practical suggestions on the clinical management of NF.

NF shares some features, such as the genetic origin of the neural tumors, cutaneous manifestations, heterogeneous phenotype and unpredictable and usually progressive natural course. However, they differ in age of onset, progression of the symptoms and prognosis. Moreover, NF clinical presentation and severity vary among patients and even between twins carrying the same NF gene mutation ${ }^{2}$. The wide range of NF clinical manifestations and the difficulties to predict the onset or the severity of new features, consequences, or complications make NF management a real clinical challenge. Although there is no cure for NF yet, proper managements of manifestations can improve patients' quality of life.

\section{NF periodic clinical revision}

Each NF patient is unique and there is not a single standard clinical approach applicable to all patients. Considering the natural history of NF as individualized, distinctive and unpredictable, the main clinical procedure for all NF forms is periodic medical examination throughout life, aiming the early detection and treatment of possible complications.

Periodicity of medical visits should be annual, unless a new sign or symptom hasten the schedule. All NF patients should have their medical, developmental and familial histories reviewed periodically and receive appropriate genetic counseling, as well as complete physical examination, with emphasis on the cardiovascular and nervous system.

Table 1 summarizes complementary procedures for adequate clinical follow up and screening of NF1 and NF2 patients after their initial clinical evaluation. SCH annual evaluation is generally restricted to proper treatment of the pain related to new schwannomas.

Table 1. Screening procedures and age of assessment for NF1 and NF2.

\begin{tabular}{lcc}
\hline \multirow{2}{*}{ Annual screening procedures } & \multicolumn{2}{c}{ Age (years) } \\
\cline { 2 - 3 } & NF1 & NF2 \\
\hline Ophthalmologic exam & $\mathrm{TL}$ & $\mathrm{TL}$ \\
Physical examination of skin and skeleton & $\mathrm{TL}$ & $\mathrm{IN}$ \\
audiological evaluation & $0-12$ & $\mathrm{TL}$ \\
Speech evaluation & $0-12$ & $>12$ \\
Cognitive testing & $4-18$ & $\mathrm{IN}$ \\
Oral evaluation & $\mathrm{TL}$ & $\mathrm{TL}$ \\
Arterial blood pressure measurement & $\mathrm{TL}$ & $\mathrm{IN}$ \\
Electroencephalogram & $\mathrm{IN}$ & $\mathrm{IN}$ \\
\hline IN: if necessary, based on clinical signs and/or symptoms; TL: throughout life.
\end{tabular}

\section{Neurofibromatosis type 1 management}

As a general guideline, Table 2 shows a variety of NF1 features, their common consequences and possible complications that should be assessed annually3. It is worth to mention that most of individuals with NF1 will not present complications throughout their lives. Further, on this chapter, these issues will be discussed separately.

\section{Mortality and associated conditions}

NF1 impact on mortality is not completely clear, although it seems that younger individuals with more severe clinical presentation suffer greater impact on life expectancy. Some cohort studies have reported a mean reduction of 8 to 15 years $^{4,5}$ while studies based on death certificates have shown a greater reduction (of about 16 to 20 years) ${ }^{6,7}$ in life expectancy. The leading reported cause of early death in all age groups is malignant neoplasm, especially malignant peripheral nerve sheath tumor (MPNST). Therefore, special attention along the annual medical evaluation is recommended for this tumor, as well as for gastrointestinal stromal tumor and breast carcinoma in younger individuals with $N F 1^{8}$.

Vasculopathy is an important cause of death in younger age groups ${ }^{6}$ and it is an important cause of sudden death in asymptomatic patients ${ }^{9}$, caused mainly by vascular fibromuscular dysplasia and malformations ${ }^{10}$ rather than atherosclerotic related conditions ${ }^{11}$.

Hypertension is associated with mortality, it is significantly associated with mortality in NF1 and blood pressure should be checked in every medical visit. A frequent cause of hypertension in NF1 is renal artery stenosis, especially in pediatric population. Moreover, coarctation of aorta and pheochromocytomas represent important differential diagnosis in NF1 hypertensive individuals ${ }^{12,13}$.

\section{NF1 cosmetic problems}

CAL spots and freckling are not likely to cause physical complaints, though they may be cosmetically bothersome to affected patient. Lisch nodules are best visible with appropriate devices and they do not cause vision impairment. Macrocephaly may cause cosmetic concerns, though no specific intervention is usually required. There is no surgical or approved drug treatment for CAL spots, freckling or macrocephaly.

Disfigurements are usually associated with growing plexiform neurofibromas (PNF) and they represent a major challenge in NF1 management. Plastic surgery is still the current best option. However, unfortunately, most cases will achieve poor results.

\section{NF1 related tumors}

Neurofibromas are the hallmark of NF1 (found in 99\% of patients) and their management differs depending on the type of neurofibroma ${ }^{14}$. 
Table 2. NF1 major features, consequences and complications (adapted from Riccardi, 2010).

\begin{tabular}{|c|c|c|c|}
\hline $\begin{array}{l}\text { Diagnosis criteria } \\
\text { features }\end{array}$ & Site & Possible Consequences & Possible Complications \\
\hline CAL, freckling & Skin & Cosmetic & \\
\hline Lisch nodules & Eye & & \\
\hline \multirow[t]{5}{*}{ Neurofibromas } & Cutaneous & Cosmetic, itching & \\
\hline & Subcutaneous, nerve & Pain, tenderness & Weakness, MPNST \\
\hline & Plexiform, paraspinal & Pain, weakness & Pain, MPNST, early death \\
\hline & Plexiform, diffuse $\vee$ nerve & Cosmetic & Disfigurement, MPNST, early death \\
\hline & Plexiform, diffuse, face/neck/trunk/limb & Weakness, cosmetic & Pain, MPNST disfigurement, early death \\
\hline \multirow[t]{2}{*}{ Glioma/ astrocytoma } & Optical & Visual loss & Visual loss, chemotherapy \\
\hline & Cerebral, posterior fossa, spinal cord & Neurologic symptoms & Neurologic deficit, chemotherapy \\
\hline \multirow[t]{2}{*}{ Osseous dysplasia } & Sphenoid wing & Facial deformity & Disfigurement, vision loss \\
\hline & Flat and long bones & Bowing, pseudoarthrosis & Amputation \\
\hline \multicolumn{4}{|l|}{ Other related features } \\
\hline $\begin{array}{l}\text { Central } \\
\text { nervous system } \\
\text { disorganization }\end{array}$ & Brain, posterior fossa, spinal cord & $\begin{array}{l}\text { Cognitive and speech deficits, } \\
\text { seizures, MRI/HT,WS, general } \\
\text { low coordination, circadian } \\
\text { compromise, behavioral problems }\end{array}$ & $\begin{array}{l}\text { Mental retardation, } \\
\text { attention deficit/hyperactivity disorder } \\
(\mathrm{ADHD}) / \text { autism spectrum disorder (ASD) }\end{array}$ \\
\hline \multirow[t]{8}{*}{ Other dysplasias } & Macrocephaly, brain & Cosmetic & \\
\hline & Vertebral & Dystrophic scoliosis & $\begin{array}{l}\text { Weakness, paralysis, multiple surgery } \\
\text { need }\end{array}$ \\
\hline & Thoracic & Pectus excavatum & Surgery need \\
\hline & Limbs & Genu varum/valgum & Surgery need \\
\hline & Vascular cerebral & Neurologic symptoms & Stroke \\
\hline & Vascular renal & Hypertension & Heart disease \\
\hline & Vascular Gastrointestinal & Ileous, pain, hemorrhage & Varied \\
\hline & Aqueductal stenosis, brain & Hydrocephalus, headache & Cranial hypertension \\
\hline \multirow[t]{2}{*}{ Tumor predisposition $(*)$} & $\begin{array}{l}\text { Blood } \\
\text { Gastrointestinal } \\
\text { Breast }\end{array}$ & $\begin{array}{l}\text { Leukemia, } \\
\text { GIST } \\
\text { Cancer }\end{array}$ & $\begin{array}{c}\text { Surgery and } \\
\text { chemotherapy need, death }\end{array}$ \\
\hline & Pheochromocytomas & $\begin{array}{c}\text { Hypertension, hyperadrenergic } \\
\text { status }\end{array}$ & Varied, including death \\
\hline Congenital heart defect & Heart & Congestive heart failure & Surgery need, death \\
\hline
\end{tabular}

CAL: cafe au lait spots; MPNST: malignant peripheral nerve sheath tumor; MRI/HT WS: T2-weighted hyperintensities in magnetic resonance image; $\left.{ }^{*}\right)$ Tumor predisposition [Lin \& Gutmann, 2013]; GIST: gastrointestinal stromal tumor.

Neurofibromas commonly occur in the skin and may be cutaneous or subcutaneous. They often arise in later childhood, especially in early puberty, and increase in size and number during adolescence and adulthood ${ }^{15}$. Neurofibromas of the skin may affect patient appearance and self-image and they may impair function, depending on size and location. Surgery is the consensus treatment option for cutaneous and subcutaneous neurofibromas. Nevertheless, Vincent M. Riccardi has been strongly advocating that oral ketotifen fumarate long-term treatment could reduce the cutaneous and subcutaneous neurofibromas in number and size (personal communication during IV International NF Symposium, Belo Horizonte, Brazil, 2014), which deserves further studies to become a consensus.

Subcutaneous neurofibromas present some risk of malignant transformation and may cause pain when pressured. When located in deeper nerves, they may also cause neurological deficits ${ }^{10,16}$.
Spinal neurofibromas may develop at any level of the spinal cord and can cause neurological impairment due to compression of the spinal cord or nerve root. Spinal neurofibromas present a risk of malignant transformation into MPNST. So far, there is no specific treatment for spinal neurofibromas and they are usually surgically managed, when it is necessary and possible ${ }^{10}$.

Plexiform neurofibromas (PNF) can cause nerve compression, disfigurement and may impair organ function due to size and increasing volume. PNF is congenital, as they arise from embryonic Schwann cells, and require monitoring because of their nearly $10 \%{ }^{17}$ to $50 \%{ }^{18}$ lifetime chance of malignant transformation into MPNST ${ }^{19}$. Surgery is the treatment of choice for symptomatic PNF, although bleeding risk must be considered, as well as remaining scars. Complete excision of the tumor is usually not possible.

MPNST generally emerge from pre-existing PNF, but it may occur de novo. It is usually diagnosed in adulthood and its occurrence in childhood and adolescence is uncommon. 
MPNST treatment consists of tumor surgical removal (with clear margins if feasible), as it is done for any other soft tissue tumor. The successful treatment depends on complete surgical excision. Adjuvant radiotherapy provides local control and may delay the onset of recurrence, but has little effect on long-term survival. Adjuvant radiotherapy should be given whenever possible for intermediate to high-grade lesions and for low-grade tumors after a marginal excision ${ }^{10}$. Systemic chemotherapy has not been proved to offer benefits, except in some specific scenario of palliative care for metastatic disease. Nevertheless, MPNST are very aggressive tumors and all current treatments have shown poor results: the five-year overall survival rate of patients with MPNSTs has been reported to range from $23 \%$ to approximately $50 \%{ }^{20}$. Figure 1 proposes an algorithmic approach to work up and management of neurofibromas.

\section{GLIOMAS}

\section{Optical Pathways Gliomas (OPG)}

OPG are histologically benign pilocytic astrocytomas and they are the commonest central nervous system NF1 tumor. OPG affects $15 \%-30 \%$ of patients, among which $50 \%$ have symptoms, and 5\%-12\% present with visual problems, such as: reduced visual acuity, reduced color perception, abnormal pupil reflex, visual fields defects, papillary edema, optical nerve atrophy and abnormal evoked visual potential. Most OPG in NF1 have a benign course and a better prognosis than OPG in non-NF1 individuals ${ }^{21}$.

Figure 2 shows a proposed follow up and treatment algorithm for OPG. Treatment should be initiated if the patient presents with progressive visual loss, proptosis or life-threatening intracranial compression. Chemotherapy with carboplatin and vincristine is the treatment of choice, despite a

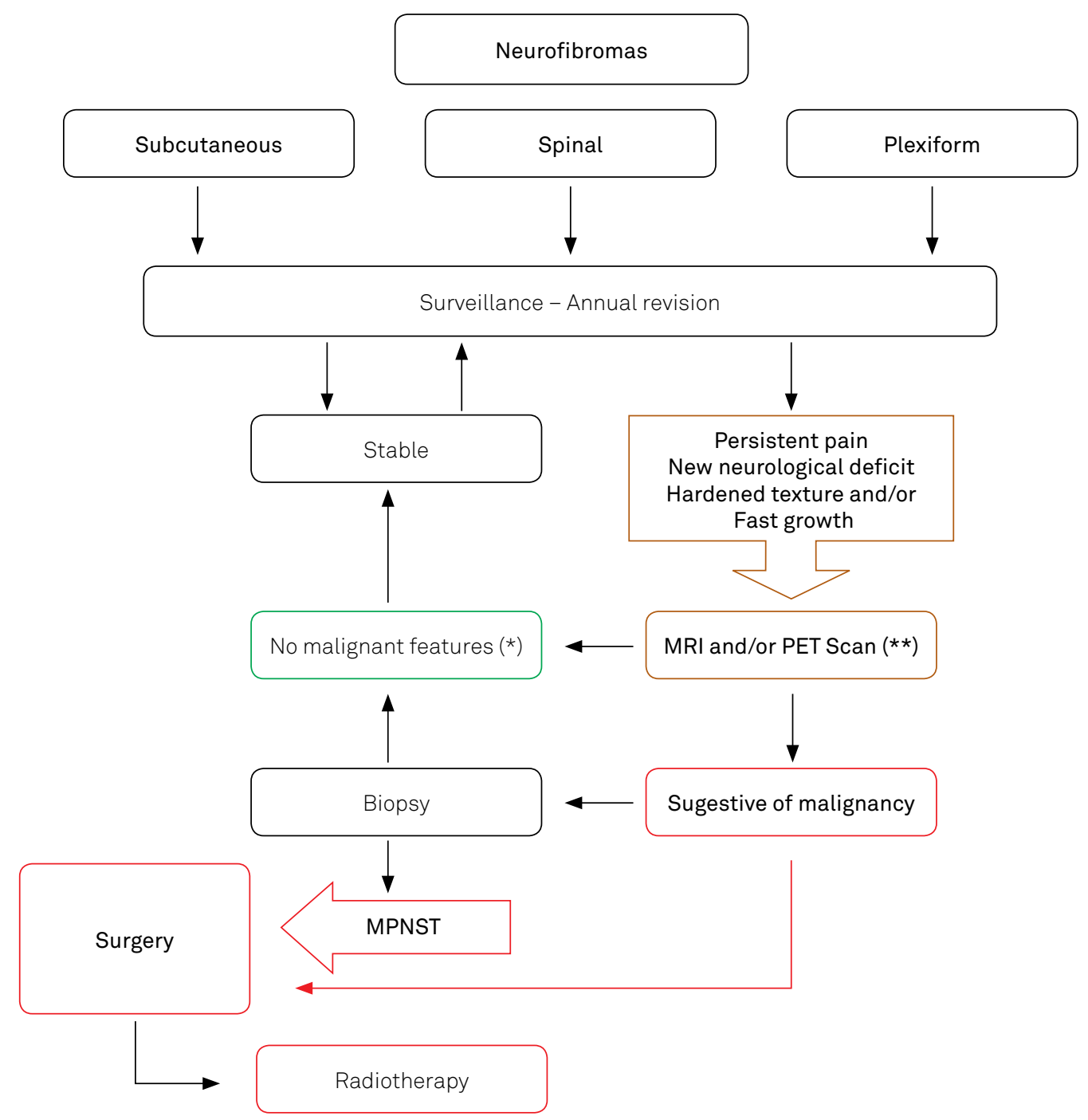

MRI: magnetic resonance imaging; PET Scan: positron emission tomography with computed tomography scan; MPNST: malignant peripheral nerve sheath tumor. (*) Only a portion of large plexiform neurofibromas undergoes malignant transformation. Therefore, an incisional biopsy may provide false-negative results for malignancy; for atypical neurofibromas, known as precursors of MPNST, radical surgery should also be considered; (**) PET Scan especially if more than one body segment is involved.

Figure 1. Proposed treatment algorithm for neurofibroma. 


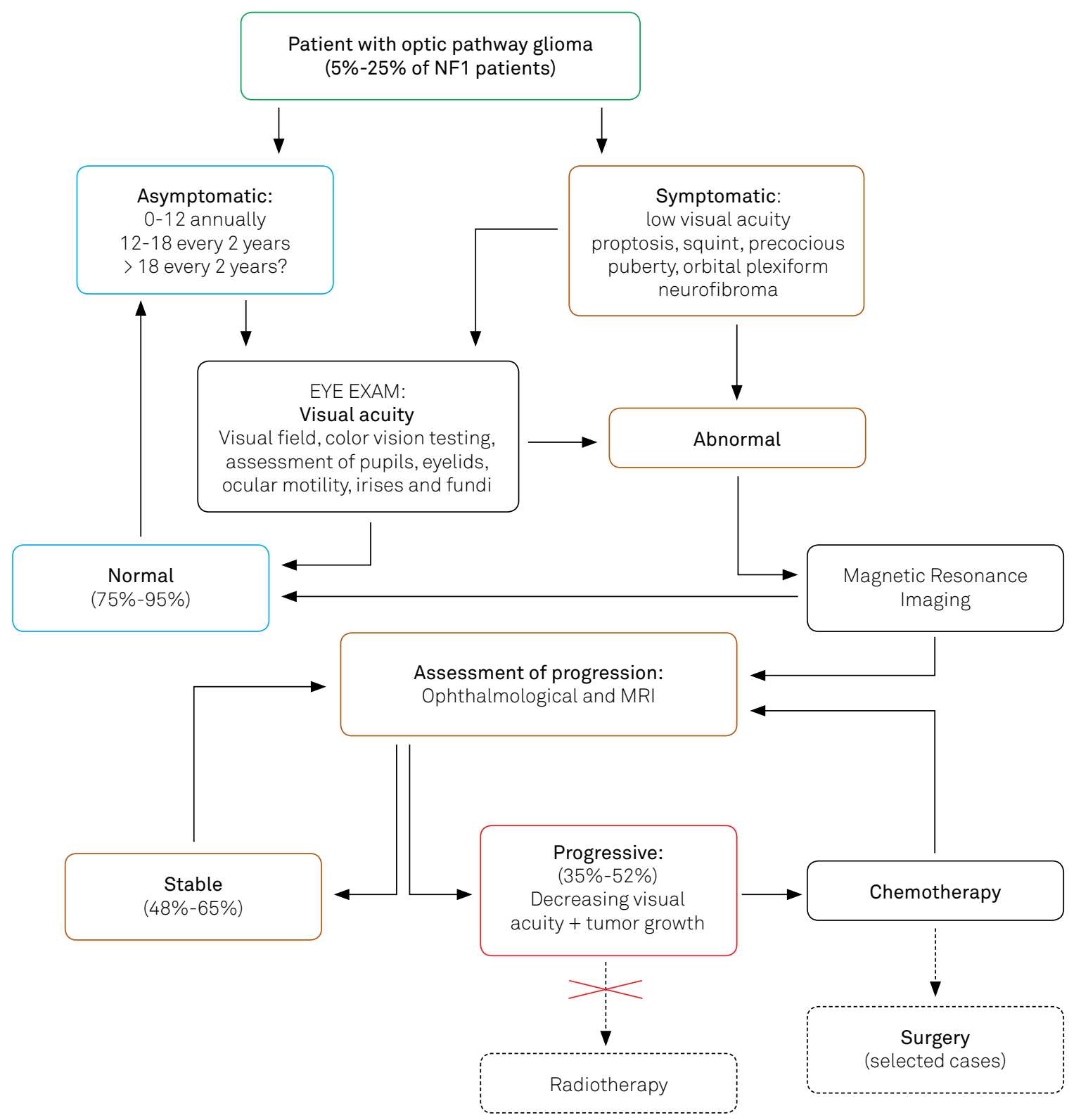

Figure 2. Proposed follow up and treatment algorithm for optical pathways gliomas in NF1.

recurrence rate of $50 \%$. Radiotherapy have been used as an option for chemotherapy failure, but it has been progressively abandoned because of its inefficacy and side effects, such as learning deficits, vascular cerebral disease and new tumor growth. Specific situations, such as severe proptosis, can benefit from surgical treatment ${ }^{21,22}$.

\section{Precocious puberty}

Most patients with NF1 undergo normal pubertal development, but it may occur late or prematurely. NF1 children have a $3 \%$ risk of developing precocious puberty (defined as accelerated linear growth at age $<7$ in girls, and $<9$ in boys) and the presence of an OPG increases this risk to $30 \%$, especially when it involves the optic chiasm (39\%). NF Specialist must confirm precocious puberty diagnosis through bone age and serial luteinizing hormone measurements.

\section{OTHER TUMORS}

$\mathrm{NF} 1$ is also associated with greater incidence of other tumors such as astrocytomas and glioblastomas, pheochromocytomas, sarcomas, gastrointestinal stromal tumor, neuroendocrine and neuroectodermal tumors (carcinoid tumor, medullar thyroid carcinoma, c-cell hyperplasia) and hematopoietic tumors (juvenile chronic myeloid leukemia, juvenile xanthogranuloma, acute lymphocytic leukemia, non-Hodgkin lymphoma). The management of these tumors requires specialized knowledge beyond the objectives of the present text.

\section{Seizures in NF1}

Seizures are common in individuals with NF1 and are mostly benign. The prevalence of seizures in the general population is $0.68 \%$, while most studies suggest a prevalence of 
6\%-7\% in NF1. Seizures can be overlooked in NF1 because routine EEG might be normal, and prolonged video EEG monitoring is often required. Among NF1 patients with seizures, $40 \%$ of them will have the onset of symptoms before the age of five. The seizures peak incidence differs between $\mathrm{NF} 1$ and general population, in which there is sharp drop of the rate of seizures after the age of four, and it peaks again after the age of 65 , but there is a lack of seizures in NF1 older age groups.

The etiology of seizures in NF1 of patients is unknown but it may be associated with underlying cortical dysplasia ${ }^{21}$ and, in a small number of patients, with tumors and vascular diseases. In addition, NF1 patients with mental retardation, autism, severe behavioral and major emotional problems are at an even higher risk for seizures.

Different studies have shown that only a relatively small percentage of patients with NF1 had another family member with seizures, suggesting that most of the tendency for seizures in this population may be actually related to NF1 and not to some other genetic predisposition ${ }^{23}$. Most patients will achieve good control of the seizures, but clinicians should be aware of the increased risk of osteoporosis in NF1 patients when prescribing anticonvulsants ${ }^{21}$.

\section{NF1 cognitive and behavioral features}

Most individuals with NF1 have a normal life, but cognitive problems are a common neurological complication ${ }^{24}$. Up to $80 \%$ of NF1 children experience moderate to severe impairment in one or more cognitive domains, including visuoperceptual abilities, processing speed, attention, motor control, language, and executive functions ${ }^{25,26}$. Despite the existence of studies reporting improvement of cognition in adulthood, cognitive deficits are likely to be an important feature of NF1 across lifespan ${ }^{27}$.

Individuals with NF1 usually present IQ levels in the low-average normal range ( 90 IQ points), and an increased incidence of intellectual disability (6\%-7\%), learning disabilities (50\%-70\%), Attention Deficit/Hyperactivity Disorder (ADHD), and autism-spectrum disorders ${ }^{24}$. Nearly $50 \%$ of NF1 patients meet clinical diagnostic criteria for ADHD, but it remains unclear if it is a real comorbid disorder or just a cognitive-behavioral phenotype of NF1. Nevertheless, treatment of ADHD symptoms may be effective in NF1 patients $^{28}$. NF1 behavioral problems could involve sleep disturbance, impaired socialization, and may lead to low selfesteem and poor interpretation of social cues ${ }^{26}$. Behavioral symptoms in NF1 seem to be closely related to their cognitive deficits.

The biologic underpinnings of cognitive performance are difficult to identify given the complexity of NF1 phenotype ${ }^{29}$. However, findings of brain abnormalities such as reduced white matter integrity, macrocephaly, abnormal gamma-aminobutyric acid activity, among others have provided converging evidences for impaired communication between the neural regions, and early myelin dysfunction in NF1 has been hypothesized to underlie cognitive deficits. In addition, the NF1 cognitive profile may be related with independently inherited genetic modifiers ${ }^{30}$ and all cognitive impairments are considered a major source of decreased quality of life in NF1 childhood ${ }^{31}$.

Cognitive deficits, language disorders and learning disabilities are important targets for pharmacological treatment. Based on a previous Lovastatin learning disabilities treated mouse model (Nf1 + / -), the Acosta and colleagues Phase I preliminary results of Lovastatin in NF1 children showed improvement in verbal and nonverbal memory in most of treated patients ${ }^{32}$.

Therefore, there is a need of a professional coordinator, who should keep a close report with teachers, educational psychologists, occupational therapists, speech and language therapists and pediatricians, to make sure that these children are getting optimum assessment and corrective support, should monitor children with NF1.

\section{Communication disorders are different in NF1 and NF2}

Although hearing loss is the main symptom in NF2 patients, communication disorders are also important complication in NF1 patients. NF1 patients present difficulties in producing speech sounds, problems with voice quality and auditory processing disorders. They may present with articulation disorders, hypernasality (inability to obtain adequate closure of the velopharyngeal port during sound production), stuttering, fast rate of speech, hoarseness, atypically loud volume, harshness or creak, weakness and breathiness ${ }^{33}$. These features may derive from various problems such as poor coordination of articulatory muscles and breathing control and/or inability to synchronize the complex motor patterns required for speech ${ }^{34}$.

Individuals with NF1 show delayed language development and slow acquisition of vocabulary with syntactic, semantic and phonological errors. A study with Brazilian individuals with NF1 showed auditory processing disorder in $100 \%$ of the patients, which was correlated with learning deficits $^{35}$. Adults with NF1 presented with orofacial motor function impairment (that can directly affect breathing, chewing and speech), and reduced electrical potential of the masseter muscle during teeth clenching ${ }^{36}$. Individuals with NF1 should be evaluated and followed periodically by audiologist and speech therapist. Specific therapeutic interventions targeting these communication disorders in NF1 are yet to be proved efficient.

\section{Psychosocial aspects related to NF1}

Studies concerning psychosocial features and aspects of family relationships in NF1 are increasing in number. Since the 1980s, some studies emphasized the need to better understand NF1 and its psychosocial consequences, motivated by its unpredictability, the uncertainties and little control 
over the natural course of the disease, along with prejudice, all of which could lead to social isolation, anxiety, fear and doubts about a possible professional career. These consequences can affect both patients and their families ${ }^{37}$.

The wide range of somatic and psychosocial symptoms might be associated with the psychological features of children and teenagers with NF1. Some of the features are emotional immaturity, deficits in social skills, as well as shyness, problems with entering the labor market and with the establishment of sexual-affective relationships. Psychosocial impairment related to aesthetic changes (neurofibromas and CAL spots) has been described, possibly because these are easily identifiable clinical features with immediate psychological impact. Nevertheless, physical and cognitive symptoms should be considered separately when analyzing its impact on the psychosocial and emotional aspects, as well as on the subjective experiences of individuals with $\mathrm{NF}^{38}$.

Common NF1 associated psychological patterns need appropriate professional intervention based in four aspects. First, by facilitating both the access and transference of information about the disease between healthcare teams and NF1 affected individuals and their families, monitoring the process through which they assimilate and take into account such information ${ }^{37}$. Second, by helping the development of more efficient strategies to cope with problems, related or not to NF1, encouraging the reduction of negative feelings and experiences in accepting the disease. Third, by mediating NF1 subjects' career plans and family planning counseling. Fourth, by mediating agreements about treatments offered, especially when it comes to complex issues. It is important to emphasize that social support should be directed to psychological, social and economic aspects of the patients themselves and of the people in their lives.

\section{NF1 musculoskeletal disorders}

Besides sphenoid and tibia bone dysplasia, which are specific to NF1 and are diagnostic criteria, other bone abnormalities are frequent in NF1 and can be challenging features to manage.

Disfigurement, fractures, dystrophic scoliosis, pseudoarthrosis, osteopenia, osteoporosis, body asymmetries, pectus excavatum, localized overgrowth, macrocephaly, and short stature have been reported in NF1 patients. Some studies have reported decreased bone mineral density ${ }^{39}$ and lower serum levels of Vitamin D in individuals with $\mathrm{NF}^{40}$, with a higher prevalence of osteopenia and osteoporosis, which could result from a general error of bone metabolism ${ }^{41}$.

In order to address these different problems, the present guideline recommends yearly clinical evaluation of the bones, and complementary tests, such as serum vitamin D and parathyroid hormone levels, imaging study of the spine, and osseous densitometry depending on any abnormalities observed in clinical examination.
Scoliosis is the most common osseous defect associated with $\mathrm{NF} 1^{42}$ with a prevalence ranging from $10 \%$ to $30 \%^{43}$. Three types of scoliosis have been observed: non-dystrophic, dystrophic and functional. The non-dystrophic scoliosis is similar to idiopathic scoliosis observed in non-NF1 individuals, and should be initially approached as so. The dystrophic scoliosis is characterized by a sharply angulated bend, involving approximately 4 to 6 vertebral levels, frequently located in the upper thoracic region, which is rapidly progressive and associated with dysplastic changes in the vertebral bodies. The functional scoliosis is caused by abnormal growth of a limb. MRI of the spine allows early identification of vertebral dysplasia that was not initially visualized by radiography and aids the recognition of intraspinal and paraspinal soft tissue lesions, such as intraspinal neoplasm, dural ectasia and lateral meningocele, commonly associated with dystrophic scoliosis.

Other frequent NF1 osseous dysplasias ${ }^{44}$ are:

1) Vertebral scalloping (which consists of anterior, lateral or posterior erosion of the vertebral body, that can be associated with the presence of neurofibromas);

2) Dural ectasia and/or meningoceles;

3) Rib penciling (that is the thinning of the rib head like a pencil);

4) Elongation and tapering of the vertebral transverse processes;

5) Wedging and rotation of the vertebral bodies, interpedicular distance and neuroforaminal space;

8) Dystrophic pedicles.

The pathophysiology of the spinal dystrophic changes remains controversial, with no consensus yet whether bone changes are primary findings, intrinsic to bone remodeling, or if they represent secondary responses to the presence of foraminal and paravertebral neurofibromas. In addition, spinal involvement in NF1 comprises not only the above mentioned bone changes, but also primary or secondary involvement of the adjacent soft tissue. Primary changes are related to neural sheath tumors that can be benign (such as neurofibromas and neurofibromas) or malignant (as MPNST). Soft tissue secondary changes are represented by dural ectasia and lateral meningocele and the presence of other unrelated neural sheath tumors already described, such as medulloblastomas, astrocytomas, meningiomas and ganglioneuromas ${ }^{45}$. The high complexity of scoliosis and other bone problems in NF1 usually demand orthopedics specialist intervention. Discussing these procedures is beyond the objectives of the present text.

\section{Physical fitness in NF}

Physical fitness is correlated with life expectancy and quality of life. Fitness is the ability to perform physical activities, to work and to sustain habitual daily activities ${ }^{46}$. Health-related physical fitness is determined by aerobic capacity, body composition and musculoskeletal profile 
(flexibility, muscular strength and endurance). Aerobic capacity (as measured by the maximal oxygen uptake, reflects the functionality of respiratory, cardiovascular and muscular systems and varies amongst individuals due to genetic factors, age, sex, habitual daily levels of physical activity and health status ${ }^{47}$

It has been observed that individuals with NF1 have reduced maximal muscular force ${ }^{48}$ as well as decreased aerobic capacity $^{49}$. These observations could be related to NF1 shorter life expectancy, the poorer quality of life and the more frequent and earlier cardiovascular involvement observed in NF1, when compared to the general population ${ }^{9}$.

Fine motor coordination deficits and poorer motor proficiency have also been demonstrated in individuals with NF1 and are probably related to the neural abnormalities due to NF1 intrinsic neurofibromin deficiency. The exact causes involved in NF1 impaired physical fitness are unknown and it is also unclear whether exercise training would change these features. Recommendation for the regular practice of physical activity should follow those made for the general population, considering personal limitations related or not to NF1.

\section{Oral Manifestations in NF1}

Oral manifestations are very common in NF1 and have been reported to occur in $72 \%-92 \%$ of patients ${ }^{51,52}$. The most common findings are enlarged fungiform papillae of the tongue, intraoral neurofibromas, and jaw alterations ${ }^{53}$. Intraoral neurofibromas are not as common as in the skin, and affect most commonly the tongue ${ }^{53}$. Many of them do not cause problems, but depending on the location and size they may be associated with oral hygiene and speech difficulties, as well as malpositioning and mobility of teeth. Intraoral neurofibromas are not so common and not as numerous as in the skin and it needs differential diagnosis with other intraoral lesions. Whenever possible, intraoral neurofibromas should undergo surgical removal (and subsequent histopathological analysis) especially those that are troubling or located on areas of trauma. When present, the treatment of oral and facial plexiform neurofibromas is more challenging ${ }^{54}$.

Jaw malformations are usually ipsilateral to facial plexiform neurofibromas, but they may also occur in the absence of this tumor and even be bilateral. Jaw alterations include widening of the mandibular canal, mandibular foramen, mental foramen and alveolar ridge; rarefaction of coronoid and condylar processes, deepening of the mandibular notch, and flat mandibular angle ${ }^{55}$. Neurofibroma may develop intraosseously, resulting in unilocular or multilocular radiolucent lesion ${ }^{53}$. Annually stomatological exam is important in NF1 patients in order to identify alterations and prevent complications.

\section{Nutritional aspects in NF}

Low body weight, short stature and macrocephaly have been observed in NF1 ${ }^{56}$. Despite NF1 anthropometric features and some anecdotal observations about nutritional behavior among individuals with the disease, the role that food and diet play in the determination of these clinical features have not been extensively studied. We could not find data on nutritional status, eating habits, dietary patterns or nutrients intake in patients with $\mathrm{NF} 2$ or $\mathrm{SCH}$.

\section{NF1 imaging studies}

Computerized tomography (CT) scans - There is a growing concern about the long-term side effects (leukemia and brain tumor) on people exposed to radiation with medical purpose ${ }^{57}$. Since NF1 is a predisposing condition to tumors and malignancy, the use of all types of ionizing radiation in individuals with NF1 is only justified when it is outweighed by the expected benefits of the scan. Whenever possible, alternative-imaging procedures that do not use ionizing radiation should be considered.

Positron emission tomography (PET-CT) - PET-CT is of great value in monitoring lesions with the potential for malignant transformation in NF1, especially in the evaluation of the symptomatic plexiform neurofibromas ${ }^{58}$. Due to the frequency and severity of MPNST associated to NF1, PET-CT scan could be useful in the following situations: a) when the plexiform tumor growth is inconsistent with the child's growth track; b) in the presence of neurological deficit; c) changes in tumor texture; and finally d) when patient reports an inexplicable and progressive pain. Magnetic resonance imaging (MRI) shows the site and extent of the tumor but does not reliably diagnoses malignancy. Therefore, ${ }^{18}$ [F] 2-fluoro-2-deoxy-D-glucose PET-CT with delayed imaging and targeted biopsy is the most sensitive and specific method for the diagnosis of MPNST in the context of $\mathrm{NF}^{21}$.

Hyperintensities in magnetic resonance imaging NF1 in children and adolescents is often associated with the appearanceofhyperintensefocionT2-weightedandisointense/hyperintense on T1-weighted (MRI/HT $2 \mathrm{WS}$ ) on encephalic MRI, without expansive effect and do not permeate by intravenous contrast. MRI/HT $/ \mathrm{HS}_{2}$ seem to correspond to pathologic areas of vacuolar or spongiotic change (caused by intramyelinic brain edema) in the cerebellum, brainstem, basal nuclei and/ or hemispheric white matter. The signal-intensity foci are often absent in the first two years of life. They can increase in number and size between 10-12 years of age, disappearing over the years, and rarely seen after twenties ${ }^{59}$.

\section{Neurofibromatosis type 2: management}

Clinical manifestations of NF2 arise predominantly during early adulthood. Early identified features include visible schwannomas on the skin (presenting as slightly elevated areas that are often so discrete they are overlooked during examination), and ophthalmological manifestations (see under). It is important to note that dermal schwannomas, unlike the neurofibromas of NF1, do not increase in size or number over time. The hallmark sign of NF2, the bilateral vestibular schwannoma (BVS), arises most often during early 
adulthood but may develop in late adolescence or even during childhood. Schwannomas affecting other cranial nerves (most commonly the trigeminal nerve), spine, and peripheral nerves as well as meningiomas, astrocytomas and ependimomas generally arise during adulthood ${ }^{60}$.

Hearing loss and/or tinnitus are the most frequent symptoms in NF2 patients. They develop bilateral vestibular schwannomas that will eventually lead to progressive sensorineural hearing loss, tinnitus and loss of balance (90\% of patients with NF2). Auditory rehabilitation of patients with NF2 with profound bilateral hearing loss can be tried with auditory brainstem or cochlear implants. After resection of a vestibular schwannoma, patients should undergo training for auditory abilities and lip reading training ${ }^{61}$.

NF2 is also a progressive condition, with a tendency to worsening over time with complications arising from increased tumor size. Most BVS will require surgical intervention that should be indicated individually depending on age, tumor size, and complications. Figure 3 shows a flowchart with practical suggestions for the management of BVS in NF2. Schwannomas affecting other cranial nerves should be left untouched unless they cause symptoms or pain, and generally they are easier to address surgically, given that they do not invade the nerve and therefore can be removed without risk of permanent disability or impairment. Astrocytomas, ependymomas, and meningiomas associated to NF2 are slow-growing tumors that may take years to cause symptoms ${ }^{60}$.

\section{Ocular Findings in NF2}

Periodical ophthalmological examination conducted in suspected individuals and their relatives is useful to make NF2 precocious diagnosis and to establish its prognosis, as well as to the management of NF2 affected patients. NF2 presents as a spectrum of specific ocular abnormalities: juvenile posterior subcapsular/capsular or cortical lenticular opacities, disk gliomas, combined pigment epithelial and retinal hamartomas, epiretinal membrane and optic nerve sheath meningiomas (ONSM). It was observed that early detection of NF2 specific ocular abnormalities in childhood $(<18$ years old) is associated with a worse disease prognosis, although most of

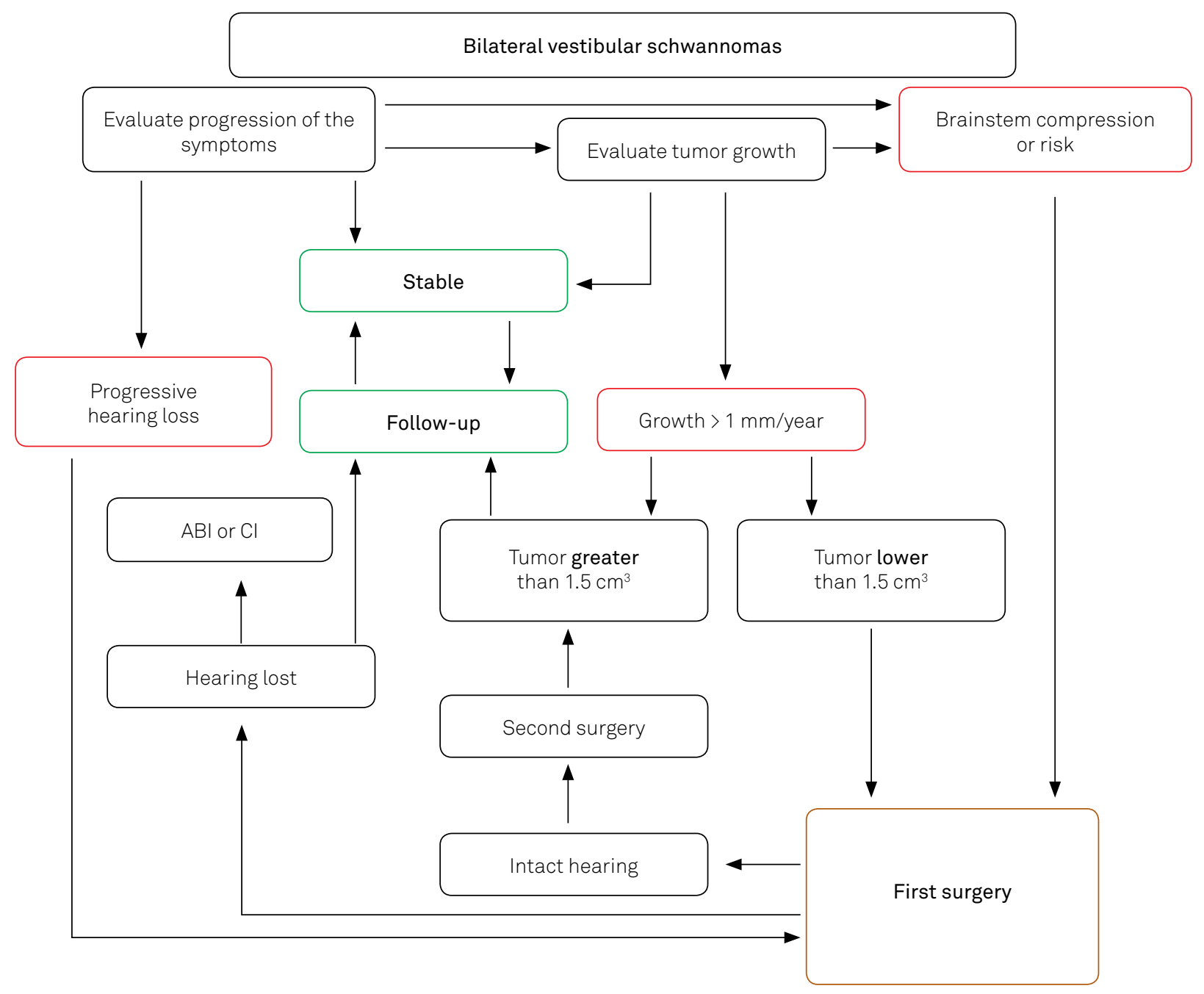

ABI: auditory brainstem implant; $\mathrm{Cl}$ : cochlear implant.

Figure 3. Adapted ${ }^{74}$ algorithm for the treatment of bilateral vestibular schwannomas. 
NF2 specific findings remain stable throughout life, except for ONSM, which usually cause progressive decrease of optic nerve function ${ }^{62}$.

Besides these NF2 specific findings, other ocular abnormalities may be secondary to coexisting intracranial or orbital tumors, like disk edema, optic atrophy, motility disorders (such as strabismus, nystagmus or abnormal vestibulo-ocular reflex), pupil dysfunction, lid dysfunction (such as lagophthalmos, ptosis or lid retraction), reduced corneal sensation, exophthalmos, corneal exposure and neurotrophic keratopathy. These NF2 secondary sings varies widely among patients, but they are important indicators of progression of intracranial tumors, because oculomotor deficits are related to BVS and intracranial tumors size.

Considering its great specificity and sensibility in diagnosis, prognosis and management, eye examination should be performed every year or twice yearly according to the findings. As survival rates have risen, eye examination becomes increasingly important as the disease progresses and hearing decreases. Conversely, the examination interval may be extended to every two years in individuals with adult onset NF2 and less than two additional CNS tumors ${ }^{62}$.

\section{Schwannomatosis: management}

Schwannomatosis is characterized by the development of multiple schwannomas (spinal, peripheral, intracranial) in the absence of vestibular schwannomas, among which $50 \%$ become symptomatic between 20 and 30 years of age ${ }^{63}$. Individuals with $\mathrm{SCH}$ should undergo yearly follow-up consultation with a specialist in order to evaluate disease progression. As many schwannomas cause pain, special attention should be directed to new onset or worsening of pain along with neurological examination. MRI studies of the brain (T2/Flair + Stir sequences), spine, and peripheral lesions are useful to monitor the development of the schwannomas.
Whole body MRI is particularly useful in this patient population. The first three diagnosed cases of SCH in Brazilian individuals have been recently reported ${ }^{64}$.

No references were found addressing physical fitness and its determinants in NF2 and/or Schwannomatosis. However, given the balance impairment observed in individuals with NF2 and chronic neuropathic pain, often observed in Schwannomatosis, we could expect health-related physical fitness to be also affected by these diseases.

\section{Pain management in NF1, NF2 and SCH}

Pain is a common complaint in NF1, NF2 and especially in patients with SCH. Pain mechanism differs depending on the type of disease and its management is a challenging issue. Table 3 shows possible mechanisms and treatments of the pain in NF.

\section{Molecular biology and potential treatments}

Currently, there are no effective drug treatment to prevent or reverse NF1, NF2 and SCH typical features. Considering features, consequences and complications, early detection of manageable complications and genetic counseling are the best option. Among the many clinical features related to NF1, plexiform neurofibromas constitute a major cause of clinical complications, since their growth can produce functional impairment and cosmetic deformities, as well as a greater risk to develop a MPNST. Clinical trials testing different drugs have been conducted, seeking an effective pharmacological treatment for patients with NF1 and NF2.

Proteins of the mTOR (mammalian target of rapamycin) pathway are a promising therapeutic target for NF1 pharmacological treatment. MTOR protein plays an important role in regulating tumor cells division and blood vessel growth. Several studies have investigated the role of rapamycin, an

Table 3. Proposed NF pain management.

\begin{tabular}{|c|c|c|c|c|}
\hline \multirow{2}{*}{$\begin{array}{l}\text { Disease } \\
\text { NF1 }\end{array}$} & \multicolumn{2}{|c|}{ Pain characteristic } & \multirow{2}{*}{$\begin{array}{c}\text { Mechanism } \\
\text { Hypertension brain? }\end{array}$} & \multirow{2}{*}{$\begin{array}{c}\text { Managments } \\
\text { Imaging studies/ surgical }\end{array}$} \\
\hline & Headache & Acute & & \\
\hline & & & Aqueductal stenosis? & \\
\hline & & & Glioma growing? & \\
\hline & & Chronic & Unknown & Analgesics \\
\hline & Peripheral (Neuropathic) & Acute & Plexiform malignant transformation into MPNST? & Imaging studies/ surgical (*) \\
\hline & & Chronic & Plexiform & Surgical and/or analgesics \\
\hline & & & Spinal compression & \\
\hline & & & Glomus tumor & \\
\hline \multirow[t]{4}{*}{ NF2 } & Headache & Acute & $\begin{array}{c}\text { Schwannomas growing? Hypertension brain? } \\
\text { Meningiomas? }\end{array}$ & Imaging studies/ surgical (**) \\
\hline & & Chronic & Unusual & Analgesics? \\
\hline & Peripheral (Neuropathic) & Acute or chronic & Schwannomas growing? & Surgical and/or analgesics \\
\hline & & & Spinal compression? & \\
\hline $\mathrm{SCH}$ & Peripheral (Neuropathic) & Acute or chronic & Schwannomas & Surgical \\
\hline
\end{tabular}


mTOR inhibitor protein, which regulates angiogenesis, nutritional needs and cell growth. Johannessen and colleagues demonstrated in a mouse model that rapamycin inhibits the growth of aggressive malignant tumors associated with $\mathrm{NF} 1^{65}$. Another pre-clinical study on optic glioma in NF1 demonstrated that pharmacological inhibition of the mTOR pathway resulted in decrease of tumor cell proliferation, and tumor volume ${ }^{66}$. Encouraging results were obtained using rapamycin in a NF1 mouse model with MPNST ${ }^{67}$.

Sorafenib (a multikinases inhibitor administered orally) shows activity against a variety of tyrosine kinase receptors (including VEGFR, PDGFR, FLT3, c-Kit and Ret) and inhibits angiogenesis inducing cell death ${ }^{68}$. Angiogenesis is an important mechanism for tumor development, being responsible for the nutritional supply for tumor cells. Pre-clinical studies using sorafenib, in genetically modified animals with NF1 and plexiform neurofibromas, demonstrated a significant reduction in tumor volume ${ }^{69}$. However, preliminary data from a Phase I clinical trial that is using sorafenib to address inoperable plexiform neurofibromas in children with NF1, reports intolerance to sorafenib at substantially lower doses than those usually used in the treatment of children and adults with malignant solid tumors, thereby limiting its use in pediatric patients with neurofibromatosis ${ }^{70}$.

Unlike what occurs in some low-grade NF1 tumors responsible to chemotherapy, NF2 associated tumors have been treated exclusively with surgery and radiotherapy. Therefore, some studies have been searching for therapeutics targets in NF2. A pre-clinical study demonstrated that inhibition of EGFR/ErbB2 (a transmembrane glycoprotein hyperexpressed and activated in vestibular schwannomas) using lapatinib produced antitumor activity on schwannomas. The preliminary results of a Phase II study to assess the antitumor activity of lapatinib in patients with NF2 showed that lapatinib presented antitumor activity, improvement of auditory responses and it was well-tolerated ${ }^{71}$.
Vascular endothelial growth factor - VEGF (a key regulator of tumor angiogenesis) and its receptor (VEGFR-1) have been detected in vestibular schwannomas in correlation with tumor growth rates. Plotkin and colleagues conducted a retrospective analysis of 10 patients with NF2 and bilateral schwannomas treated with bevacizumab (a monoclonal antibody that blocks the action of VEGF) showing shrinkage of the vestibular schwannomas in 9 of 10 patients. Updated data from this study showed that of 31 patients treated and followed up 57\% showed hearing improvement and in 55\% there was radiological response concerning the volume of the schwannomas ${ }^{73}$. Preclinical studies have shown that EGFR and VEGF signaling pathways are functionally linked, which could justify the design of future clinical trials with the combination of lapatinib and bevacizumab targeting vestibular schwannomas in NF2.

\section{CONCLUSION}

The present text proposed some practical suggestions for managing the most prevalent NF problems. The rarity of NF and extreme variability in its phenotype expression will require very specialized support in many cases. NF are part of the thousands of rare human diseases, which progressively demand well connected reference centers for information, treatment, genetic counseling and improvement in the quality of life of the affected individuals.

\section{ACKNOWLEDGMENT}

Dr. Vincent M Riccardi, from The Neurofibromatosis Institute, California, USA, for his suggestions and valuable insights.

\section{References}

1. Rodrigues LO, Batista PB, Goloni-Bertolo EM, Souza-Costa D, Eliam L, Eliam M et al. Neurofibromatosess: part 1- diagnosis and differential diagnosis. Arq Neuropsiquiatr. 2014;72(3):241-50. http://dx.doi.org/10.1590/0004-282X20130241

2. Friedman J, Riccardi V. Clinical and epidemiological features. In: Friedman J, Gutmann D, Collin M, Riccardi V, editors. Neurofibromatosis: phenotype, natural history, and pathogenesis. 3rd ed. Baltimore:The Johns Hopkins University Press; 1999. p. 29-86.

3. Riccardi VM. Neurofibromatosis type 1 is a disorder of dysplasia: the importance of distinguishing features, consequences and complications. Birth Defects Res A Clin Mol Teratol. 2010;88(1):9-14. http://dx.doi.org/10.1002/bdra.20616

4. Sørensen SA, Mulvihill JJ, Nielsen A. Long-term follow-up of von Recklinghausen neurofibromatosis: survival and malignant neoplasms. N Engl J Med. 1986;314(16):1010-5. http://dx.doi.org/10.1056/NEJM198604173141603
5. Evans DG, O'Hara C, Wilding A, Ingham SL, Howard E, Dawson

$J$ et al. Mortality in neurofibromatosis 1 in North West

England: an assessment of actuarial survival in a region of the UK since 1989. Eur J Hum Genet. 2011;19(11):1187-91. http://dx.doi.org/10.1038/ejhg.2011.113

6. Rasmussen SA, Yang Q, Friedman JM. Mortality in neurofibromatosis 1: an analysis using U.S. death certificates. Am J Hum Genet. 2001;68(5):1110-8. http://dx.doi.org/10.1086/320121

7. Masocco M, Kodra Y, Vichi M, Conti S, Kanieff M, Pace M et al. Mortality associated with neurofibromatosis type 1: a study based on Italian death certificates (1995-2006). Orphanet J Rare Dis. 2011;6(1):1-10. http://dx.doi.org/10.1186/1750-1172-6-11

8. Lin AL, Gutmann DH. Advances in the treatment of neurofibromatosis-associated tumours. Nat Rev Clin Oncol. 2013;10(11):616-24. http://dx.doi.org/10.1038/nrclinonc.2013.144 
9. Friedman JM, Arbiser J, Epstein JA, Gutmann DH, Huot SJ, Lin AE et al. Cardiovascular disease in neurofibromatosis 1: report of the NF1 Cardiovascular Task Force. Genet Med. 2002;4(3):105-11. http://dx.doi.org/10.1097/00125817-200205000-00002

10. Oderich GS, Sullivan TM, Bower TC, Gloviczki P, Miller DV, Babovic-Vuksanovic D et al. Vascular abnormalities in patients with neurofibromatosis syndrome type l: clinical spectrum, management, and results. J Vasc Surg. 2007;46(3):475-84. http://dx.doi.org/10.1016/j.jvs.2007.03.055

11. Rodrigues LO, Rodrigues LO, Castro LL, Tezende NA, Ribeiro AL. Non-invasive endothelial function assessment in patients with neurofibromatosis type 1: a cross-sectional study. BMC Cardiovasc Disord. 2013;13(1):1-6. http://dx.doi.org/10.1186/1471-2261-13-18

12. Souza JF, Toledo LL, Ferreira MCM, Rodrigues LO, Rezende NA. Neurofibromatose tipo 1: mais comum e grave do que se imagina. Rev Assoc Med Bras. 2009 b;55(4):394-9. http://dx.doi.org/10.1590/S0104-42302009000400012

13. Williams VC, Lucas J, Babcock MA, Gutmann DH, Korf B, Maria BL. Neurofibromatosis type 1 revisited. Pediatrics. 2009;123(1):124-33. http://dx.doi.org/10.1542/peds.2007-3204

14. Ferner RE. The neurofibromatosis. Pract Neurol. 2010;10(2):82-93. http://dx.doi.org/10.1136/jnnp.2010.206532

15. Cunha KS, Barbosa EP, Fonseca EC. Identification of growth hormone receptor in localised neurofibromas of patients with neurofibromatosis type 1.J Clin Pathol. 2003;56(10):758-63. http://dx.doi.org/10.1136/jcp.56.10.758

16. Korf BR, Rubenstein AE. Neurofibromatosis: a handbook for patients, families, and health care professionals. 2th ed. New York: Thieme; 2005.

17. Evans DG, Baser ME, McGaughran J, Sharif S, Howard E, Moran A. Malignant peripheral nerve sheath tumours in neurofibromatosis 1.J Med Genet. 2002;39(5):311-4. http://dx.doi.org/10.1136/jmg.39.5.311

18. Park SJ, Sawitzki B, Kluwe L. Mautner VF, Holtkamp N, Kurtz A. Serum biomarkers for neurofibromatosis type 1 and early detection of malignant peripheral nerve-sheath tumors. BMC Med. 2013;11(1):109. http://dx.doi.org/10.1186/1741-7015-11-109

19. Kolberg M, Høland M, Agesen TH, Brekke HR, Liestøl K, Hall KS et al. Survival meta-analyses for $>1800$ malignant peripheral nerve sheath tumor patients with and without neurofibromatosis type 1. Neurooncol. 2013;15(2):135-47. http://dx.doi.org/10.1093/neuonc/nos287

20. Cunha KS, Caruso AC, Faria PA, Silva LE, Pires AR, Geller M et al. Malignant peripheral nerve sheath tumors: clinicopathological aspects, expression of p53 and survival. Clinics (Sao Paulo). 2012;67(8):963-8. http://dx.doi.org/10.6061/clinics/2012(08)18

21. Ferner, RE.Neurofibromatosis 1. In: Ferner RE, Huson SM, Evans DG, editors. Neurofibromatosis in clinical practice. London:Springer; 2011. p. 162.

22. Cassiman C, Legius E, Spileers W, Casteels I. Ophthalmological assessment of children with neurofibromatosis type 1. Eur J Pediatr. 2013;172(10):1327-33. http://dx.doi.org/10.1007/s00431-013-2035-2

23. SzudekJ, Birch P, Riccardi VM, Evans DG, Friedman JM. Associations of clinical features in neurofibromatosis1 (NF1). Genet Epidemiol. 2000;19(4):429-39. http://dx.doi.org/10.1002/10982272(200012)19:4<429::AID-GEPI13>3.0.CO;2-N

24. Hyman SL, Shores A, North KN. The nature and frequency of cognitive deficits in children with neurofibromatosis type 1. Neurology. 2005;65(7):1037-44. http://dx.doi.org/10.1212/01.wnl.0000179303.72345.ce

25. Hachon C, Iannuzzi S, Chaix Y. Behavioural and cognitive phenotypes in children with neurofibromatosis type 1 (NF1): the link with the neurobiological level. Brain Dev. 2011;33(1):52-61. http://dx.doi.org/10.1016/j.braindev.2009.12.008

26. Lehtonen A, Howie E, Trump D, Huson SM. Behaviour in children with neurofibromatosis type 1: cognition, executive function, attention, emotion, and social competence. Dev Med Child Neurol. 2013;55(2):111-25. http://dx.doi.org/10.1111/j.1469-8749.2012.04399.x
27. Costa DS, Paula JJ, Rezende NA, Rodrigues LO, Malloy-Diniz LF, Romano-Silva MA et al. Neuropsychological impairments in elderly Neurofibromatosis type 1 patients. Eur J Med Genet. 2014;57(5):216-9. http://dx.doi.org/10.1016/j.ejmg.2014.02.004

28. Mautner VF, Kluwe L, Thakker SD, Leark RA. Treatment of ADHD in neurofibromatosis type 1. Dev Med Child Neurol. 2002;44(3):164-70. http://dx.doi.org/10.1017/S0012162201001876

29. Pasmant E, Vidaud M, Vidaud D, Wolkenstein P. Neurofibromatosis type 1: from genotype to phenotype. J Med Genet. 2012;49(8):483-9. http://dx.doi.org/10.1136/jmedgenet-2012-100978

30. Shilyansky C, Karlsgodt KH, Cummings DM, Sidiropoulou K, Hardt $M$, James AS et al. Neurofibromin regulates corticostriatal inhibitory networks during working memory performance. Proc Natl Acad Sci USA. 2010;107(29):13141-6. http://dx.doi.org/10.1073/pnas.1004829107

31. North KN, Riccardi V, Samango-Sprouse C, Ferner R, Moore B, Legius E et al. Cognitive function and academic performance in neurofibromatosis. 1: consensus statement from the NF1 Cognitive Disorders Task Force. Neurology. 1997;48(4):1121-7. http://dx.doi.org/10.1212/WNL.48.4.1121

32. Acosta MT, Kardel PG, Walsh KS, Rosenbaum K, Gioia GA, Packer RJ. Lovastatin as treatment for neurocognitive deficits in neurofibromatosis type 1: Phase I study. Ped Neurol. 2011;45(4):241-5. http://dx.doi.org/10.1016/j.pediatrneurol.2011.06.016

33. Cosyns M, Mortier G, Janssens S, Claes K, Van Borsel J. Objective assessment of nasality in Flemish adults with neurofibromatosis type 1. Am J Med Genet. 2011;155A(12):2974-8. http://dx.doi.org/10.1002/ajmg.a.34314

34. Lorch M, Ferner RE, Golding J, Whurr R. The nature of speech and language impairment in adults with neurofibromatosis1.J Neurolinguist. 1999;12(3-4):157-65. http://dx.doi.org/10.1016/S0911-6044(99)00012-3

35. Batista PB, Lemos SM, Rodrigues LO, Rezende NA. Auditory temporal processing deficits and language disorders in patients with neurofibromatosis type 1.J Commun Disord. 2014;48:18-26. http://dx.doi.org/10.1016/j.jcomdis.2013.12.002

36. Silva CM, Souza JF, Rodrigues LOC et al. Orofacial motor function impairment and decreased electrical potential of the masseter muscle correlate with maximal handgrip force in individuals with NF1. In: Proceedings of the 2014 Children's Tumor Foundation NF Conference; 2014 Jun 7-10; Washington DC. [S.l.]. 2014. p. 87 [Poster].

37. Ablon J. Parents' responses to their child's diagnosis of neurofibromatosis 1. Am J Med Genet. 2000;93(2):136-42. http://dx.doi.org/10.1002/1096-8628(20000717)93:2<136::AIDAJMG11>3.0.CO;2-L

38. Cerello AC, Gianordoli-Nascimento IF, Moreira AH, Rocha VS, Ribeiro LM, Rezende NA. [Social representations of patients and relatives regarding type 1 neurofibromatosis. Cien Saude Colet]. 2013;18(8):2359-68. Portuguese. http://dx.doi.org/10.1590/S1413-812320130008000020

39. Stevenson DA, Moyer-Mileur LJ, Murray M, Slater H, Sheng X, Carey JC et al. Bone mineral density in children and adolescents with neurofibromatosis type 1.J Pediatr. 2007;150(1):83-8. http://dx.doi.org/10.1016/j.jpeds.2006.10.048

40. Lammert M, Friedman JM, Roth HJ, Friedrich RE, Kluwe L, Atkins D et al. Vitamin $D$ deficiency associated with number of neurofibromas in neurofibromatosis 1.J Med Genet. 2006;43(10):810-3. http://dx.doi.org/10.1136/jmg.2006.041095

41. Petramala L, Giustini S, Zinnamosca L, Marinelli C, Colangelo L, Cilenti G et al. Bone mineral metabolism in patients with neurofibromatosis type 1 (von Recklingausen disease). Arch Dermatol Res. 2012;304(4):325-31. http://dx.doi.org/10.1007/s00403-011-1191-3

42. Trovó-Marqui AB, Goloni-Bertollo EM, Valério NI, Pavarino-Berteli EC, Muniz MP, Teixeira MF et al. High frequencies of plexiform neurofibromas, mental retardation, learning difficulties, and scoliosis in Brazilian patients with neurofibromatosis type 1. Braz J Med Biol Res. 2005;38(9):1441-7. http://dx.doi.org/10.1590/S0100-879X2005000900020 
43. Crawford AH, Herrera-Soto J. Scoliosis associated with neurofibromatosis. Orthop Clin North Am. 2007;38(4):553-62. http://dx.doi.org/10.1016/j.ocl.2007.03.008

44. Tsirikos Al, Saifuddin A, Noordeen MH. Spinal deformity in neurofibromatosis type-1: diagnosis and treatment. Eur Spine J. 2005;14(5):427-39. http://dx.doi.org/10.1007/s00586-004-0829-7

45. Restrepo CS, Riascos RF, Hatta AA, Rojas R. Neurofibromatosis type 1: spinal manifestations of a systemic disease. J Comput Assist Tomogr. 2005;29(4):532-9. http://dx.doi.org/10.1097/01.rct.0000163705.21892.23

46. US Department of Health and Human Services, Centers for Disease Control and Prevention, National Center for Chronic Disease Prevention and Health Promotion. Physical activity and health: a report of the surgeon general. Atlanta: US Department of Health and Humans Services; 1996.

47. Lee DC, Artero EG, Sui X, Blair SN. Mortality trends in the general population: the importance of cardiorespiratory fitness. J Psychopharmacol. 2010;24(4 Suppl):27-35. http://dx.doi.org/10.1177/1359786810382057

48. Bouchard C, Shephard RJ. Physical activity, fitness, and health: the model and key concepts. In: Bouchard C, Shepard RJ, Stephens T, editors. Physical activity, fitness, and health: international proceedings and consensus statement. Champaign: Human Kinetics; 1994. p. 77-88.

49. Souza JF, Passos RLF, Guedes ACM, Rezende NA, Rodrigues LOC. Muscular force is reduced in neurofibromatosis type 1.J Musculoskelet Neuronal Interact. 2009;9(1):15-7.

50. Souza JF, Araújo CG, Rezende NA, Rodrigues LOC. Exercise capacity impairment in individuals with neurofibromatosis type 1. Am J Med Genet A. 2013;161A(2):393-5. http://dx.doi.org/10.1002/ajmg.a.35729

51. D'Ambrosio JA, Langlais RP, Young RS. Jaw and skull changes in neurofibromatosis. Oral Surg Oral Med Oral Pathol. 1988;66(3):391-6.

52. Shapiro SD, Abramovitch K, Van Dis ML, Skoczylas LJ, Langlais RP, Jorgenson RJ et al. Neurofibromatosis: oral andradiographic manifestations. Oral Surg Oral Med Oral Pathol. 1984;58(4):493-8. http://dx.doi.org/10.1016/0030-4220(84)90350-5

53. Cunha KS, Barboza EP, Dias EP, Oliveira FM. Neurofibromatosis type I with periodontal manifestation. A case report and literature review. Br Dent J. 2004;196(8):457-60. http://dx.doi.org/10.1038/sj.bdj.4811175

54. Jouhilahti EM, Visnapuu V, Soukka T, Aho H, Peltonen S, Happonen RP et al. Oral soft tissue alterations in patients with neurofibromatosis. Clin Oral Investig. 2012;16(2):551-8. http://dx.doi.org/10.1007/s00784-011-0519-x

55. Friedrich RE, Giese M, Schmelzle R, Mautner VF, Scheuer HA. Jaw malformations plus displacement and numerical aberrations of teeth in neurofibromatosis type 1: a descriptive analysis of 48 patients based on panoramic radiographs and oral findings. J Craniomaxillofac Surg. 2003;31(1):1-9. http://dx.doi.org/10.1016/S1010-5182(02)00160-9

56. Szudek J, Birch P, Friedman JM. Growth charts for young children with neurofibromatosis 1 (NF1). Am J Med Genet. 2000;92(3):224-8. http://dx.doi.org/10.1002/(SICI)1096-8628(20000529)92:3<224::AIDAJMG12>3.0.CO;2-J

57. Pearce MS, Salotti JA, Little MP, McHugh K, Lee C, Kim KP et al. Radiation exposure from CT scans in childhood and subsequent risk of leukaemia and brain tumours: $a$ retrospective cohort study. Lancet. 2012;380(9840):499-505. http://dx.doi.org/10.1016/S0140-6736(12)60815-0

58. Ferner RE, Golding JF, Smith M, Calonje E, Jan W, Sanjayanathan $\checkmark$ et al. [18F]2-fluoro-2-deoxy-D-glucose positron emission tomography (FDG PET) as a diagnostic tool for neurofibromatosis 1 (NF1) associated malignant peripheral nerve sheath tumours (MPNSTs): a long-term clinical study. Ann Oncol. 2008;19(2):390-4. http://dx.doi.org/10.1093/annonc/mdm450

59. Ferraz Filho JRL, Munis MP, Souza AS, Sanches RA, GoloniBertollo EM, Pavarino-Bertelli EC. Unidentified bright objects on brain MRI in children as a diagnostic criterion for neurofibromatosis type 1. Pediatr Radiol. 2008;38(3):305-10. http://dx.doi.org/10.1007/s00247-007-0712-x

60. Lloyd SK, Evans DG. Neurofibromatosis type 2 (NF2): diagnosis and management. Handb Clin Neurol. 2013;115:957-67. http://dx.doi.org/10.1016/B978-0-444-52902-2.00054-0

61. Monteiro TA, Goffi-Gomez MV, Tsuji RK, gomes MQ, Brito Neto RV, Bento RF. Neurofibromatosis 2: hearing restoration options. Braz J Otorhinolaryngol. 2012;78(5):128-34. http://dx.doi.org/10.5935/1808-8694.20120020

62. Bosch MM, Boltshauser E, Harpes P, Landau K. Ophthalmologic findings and long-term course in patients with neurofibromatosis type 2. Am J Ophthalmol. 2006; 141:1068-77. http://dx.doi.org/10.1016/j.ajo.2005.12.042

63. MacCollin M, Chiocca EA, Evans DG, Friedman JM, Horvitz R, Jaramillo D et al. Diagnostic criteria for schwannomatosis. Neurology. 2005;64(11):1838-45. http://dx.doi.org/10.1212/01.WNL.0000163982.78900.AD

64. Vilela S, Cotta AC, Paim JF, Champs APS, Navarro M, Rosse $D$ et al. Schwannomatose: primeiros casos relatados no Brasil. Rev Med Minas Gerais. 2013;23(4):462-6. http://www.dx.doi.org/10.5935/2238-3182.20130072

65. Johannessen CM, Johnson BW, Williams SM, Chan AW, Reczek EE, Lynch RC et al. TORC1 is essential for NF1-associated malignancies. Curr Biol. 2008;18(1):56-62. http://dx.doi.org/10.1016/j.cub.2007.11.066

66. Hegedus B, Banerjee D, Yeh TH, Rothermich S, Perry A, Rubin $\mathrm{JB}$, et al. Preclinical cancer therapy in a mouse model of neurofibromatosis-1 optic glioma. Cancer Res. 2008;68(5):1520-8. http://dx.doi.org/10.1158/0008-5472.CAN-07-5916

67. Bhola P, Banerjee S, Mukherjee J, Balasubramanium A, Arun V, Karim Z et al. Preclinical in vivo evaluation of rapamycin in human malignant peripheral nerve sheath explant xenograft. Int J Cancer. 2010;126(2):563-71. http://dx.doi.org/10.1002/ijc.24783

68. Wilhelm SM, Adnane L, Newell P,Villanueva A, Llovet Jm, Lynch M et al. Preclinical overview of sorafenib, a multikinase inhibitor that targets both Raf and VEGF and PDGF receptor tyrosine kinase signaling. Mol Cancer Ther. 2008;7(10):3129-40. http://dx.doi. org/10.1158/1535-7163.MCT-08-0013

69. Wu J, Dombi E, Jousma E, Scott Dunn R, Lindquist D, Schenell BM et al. Preclincial testing of sorafenib and RAD001 in the Nf(flox/flox); DhhCre mouse model of plexiform neurofibroma using magnetic resonance imaging. Pediatr Blood Cancer. 2012;58(2):173-80. http://dx.doi.org/10.1002/pbc.23015

70. Kim A, Dombi E, Tepas K, Fox E, Martin S, Wolters P et al. Phase I trial and pharmacokinetic study of sorafenib in children with neurofibromatosis type I and plexiform neurofibromas. Pediatr Blood Cancer. 2013;60(3):396-401. http://dx.doi.org/10.1002/pbc.24281

71. Karajannis MA, Legault G, Hagiwara M, Ballas MS, Brown $\mathrm{K}$, Nusvaum $\mathrm{AO}$ et al. Phase II trial of lapatinib in adult and pediatric patients with neurofibromatosis type 2 and progressive vestibular schwannomas. Neuro Oncol. 2012;14(9):1163-70. http://dx.doi.org/10.1093/neuonc/nos146

72. Cayé-Thomasen P, Baandrup L, Jacobsen GK, Thomsen J, Stangerup SE. Immunohistochemical demonstration of vascular endothelial growth factor in vestibular schwannomas correlates to tumor growth rate. Laryngoscope. 2003;113(12):2129-34. http://dx.doi.org/10.1097/00005537-200312000-00014

73. Plotkin SR, Merker VL, Halpin C, Jennings D, McKenna MJ, Harris GJ et al. Bevacizumab for progressive vestibular schwannoma in neurofibromatosis type 2 : a retrospective review of 31 patients. Otol Neurotol. 2012;33(6):1046-52. http://dx.doi.org/10.1097/MA0.0b013e31825e73f5

74. Blakeley JO, Evans GD, Adler J, Brackmann D, Chen R, Ferner R E et al. Consensus recommendations for current treatments and accelerating clinical trials for patients with neurofibromatosis type 2. Amer J Medl Genetics. 2012:158A:24-41. 